\title{
Gender Differences in Verbal and Visuospatial Working Memory Tasks in Patients with Mild Cognitive Impairment and Alzheimer Disease
}

\author{
M. Rosa Elosúa ${ }^{a} \quad$ María José Ciudad ${ }^{a}$ b María José Contreras $^{a}$ \\ a Universidad Nacional de Educación a Distancia (UNED), Madrid, Spain; ${ }^{b}$ Geriatrics and \\ Palliative Care, Badalona Serveis Assistencials, Badalona, Spain
}

Keywords

Alzheimer disease - Mild cognitive impairment - Gender differences - Working memory ·

Visuospatial span tasks · Verbal span tasks

\begin{abstract}
Background/Aims: To date, there are few studies on gender differences in patients with mild cognitive impairment (MCI) and Alzheimer disease (AD). In the present study, the existence of differences between sexes in verbal and visuospatial working memory tasks in the evolution of cognitive and pathological aging was examined. Method: Ninety participants took part in this study: $30 \mathrm{AD}, 30 \mathrm{MCI}$, and 30 healthy elderly participants $(50 \%$ men and $50 \%$ women). Results: There were no significant differences between men and women with AD in visuospatial tasks, whereas these differences were found within the MCI group, with the average of men achieving significantly higher results than women. In verbal tasks, there were no differences between sexes for any of the groups. Conclusion: Execution in visuospatial tasks tends to depend on gender, whereas this does not occur for verbal tasks.
\end{abstract}

(C) 2017 The Author(s)

Published by S. Karger AG, Basel

\section{Introduction}

Working memory (WM) dysfunctions can be found among the difficulties that appear in the functioning of the memory of patients with Alzheimer disease (AD) [1]. Although there are several models of WM, the model proposed by Baddeley and Hitch [2,3] is one of the most used in the neuropsychological research of cognitive aging. According to this model, the WM system includes 4 components: the phonological loop, which holds verbal information; the 
visuospatial sketchpad, which holds visual and spatial information; an episodic buffer that links the two prior components with long-term memory, and a central executive in charge of the attentional control of information.

The verbal component of WM has been one of the most studied in AD patients. In Huntley and Howard's [4] review of WM and AD, there were more studies showing significant differences in WM verbal tasks between healthy elderly and Alzheimer patients in early stages of the disease [5], or between mild and moderate phases [6], than studies not showing such differences. However, in relation to visuospatial WM tasks, research has shown that they are clearly affected in Alzheimer patients [7] and that this involvement can be found in patients with mild cognitive impairment (MCI) [8,9] and even in healthy elders [10].

However, there are currently very few studies investigating the effect of gender on verbal and visuospatial WM tasks in patients with AD and MCI. Regarding AD, Heun and Kockler [11] found that women, on average, had more difficulties in visuoconstructive skills compared to men. Moreover, women had greater deficits in verbal skills; a difference which was not expected a priori, which - according to the authors - is probably explained by a pattern of differential neuronal degeneration in men and women. These findings are collected in a metaanalysis [12] where the analysis of 253 publications showed a greater overall deterioration in women with $\mathrm{AD}$ compared to men. Regarding gender differences in $\mathrm{MCI}$, the scarcity of research is even greater. One study [13] reported that men performed better in visuospatial tasks than women, but in verbal tasks, women were better than men. The lack of research on gender differences in $\mathrm{MCI}$ is still greater than in $\mathrm{AD}$, and to date, there are no definitive studies on this issue.

The objective of the present research was to study the effect of gender on the performance of verbal and visuospatial WM tasks in MCI and $\mathrm{AD}$ patients. It was based on a previous study [14], in which a greater deterioration in the visuospatial component than in the verbal component of the WM of Alzheimer patients was obtained, without finding significant differences between sexes. Subsequently, the cognitive deterioration was enlarged with a MCI sample and also by including new verbal and visuospatial tasks. The following hypotheses were considered: (1) the performance in visuospatial tasks will be more affected in women than in men in each of the groups (AD, MCI, and normal aging); (2) the performance in verbal tasks will be more affected in women in the more advanced stages of cognitive impairment.

\section{Methods}

\section{Participants}

The study sample consisted of 90 participants. There was a group of 30 patients $(15$ men and 15 women) diagnosed with dementia due to probable AD (according to NIA-AA criteria [15]). As some patients had a very low level of schooling ( $>2$ standard deviations) and were unable to complete all of the study's tests, 14 men and 13 women were finally included. There was another group of 30 patients ( 15 men and 15 women) diagnosed with $\mathrm{MCI}$ according to Albert criteria [16].

The inclusion criteria were, in the AD group, MMSE scores $<23$ and Geriatric Dementia Scale (GDS) scores of 4-5. They met criteria for dementia due to probable AD in the category of amnestic presentation. In the MCI group, participants had MMSE scores between 27 and 24 and GDS scores of 3-4. Participants with AD and MCI were recruited from a sample of patients who attended the Neuropsychology Unit of the Geriatric and Palliative Care Service of Badalona Serveis Assistencials.

In the healthy elderly control group, there were 30 participants ( 15 men and 15 women). They had obtained an MMSE score $>27$ and/or a GDS score of 2 . 
The exclusion criteria for all participants who were taken into account were other concomitant central nervous system pathologies, chronic disabling diseases, psychiatric disorders, or severe sensory deficiencies. All patients in the AD group had been taking cholinesterase inhibitors for more than 4 weeks. Neuropsychological testing was administered under standardized conditions; a differential medication effect is therefore not expected. Patients were able to perform activities of daily living; they were not clinically depressed and they were not taking medication for it. All participants included in the study signed informed consent and participated voluntarily.

\section{Cognitive Assessment}

Mini-Mental State Examination (MMSE) [17]. This is a measurement of the general cognitive status. It consists of 30 items that include spatiotemporal orientation, repetition, attention, calculation, memory, denomination, reading, writing, and visoconstructive functions. Its scores range from 0 to 30 points.

Standard Corsi Block-Tapping Test [18]. The task is to repeat a visual sequence of fixed blocks on a board that the participant touches with his/her finger. The series start with a sequence of two blocks initially and increase at a rate of 1 per level of amplitude or difficulty (each level consists of 3 series) until the participant fails at least 2 series in 1 level. The total number of correct blocks remembered was scored.

Corsi Block-Tapping Task (with Inhibition) [14]. The participant must inhibit (not repeat) the second block of each trial, then he/she must recall the rest of the sequence in the same order. The total score of the number of correct blocks remembered was obtained.

Hooper Visual Organization Test (HVOT) [19, 20]. This visuoperceptive test measures object recognition. It consists of 30 sheets which contain drawings of everyday objects that have been cut into several pieces and placed in different positions. The participant is asked to recognize and say the name of the represented object. The scores range from 0 to 30 points.

Wechsler Memory Scale Revised [21]. The test consists of reading increasing series of digits that the subject must remember later, in serial order. The score of the total number of correct digits remembered was obtained.

Digits Task (with Inhibition) [14]. The participant must inhibit (not repeat) the second digit of each trial by recalling the whole sequence in the same order. The score of the total number of correct digits remembered was obtained.

Semantic Verbal Fluency Subtest: Animals from the Barcelona Test (TB) [22]. This classic test measures the total number of named animals belonging to a semantic category during $1 \mathrm{~min}$.

\section{Statistical Analysis}

To compare sociodemographic characteristics and cognitive impairment (MMSE) among $\mathrm{AD}, \mathrm{MCI}$, and healthy elderly patients, and to verify if there were differences, Student $t$ tests were performed for independent samples (Tables 1,2). The results indicated significant differences in MMSE scores between the 3 groups, as expected (Table 1). As there were age differences between patients with $\mathrm{AD}$ and the healthy elderly, as well as between AD and MCI patients, age was used as a covariate in all ANOVAs that were performed. No significant differences were found in years of education. There were no significant differences in the variables age, years of education, and MMSE in the comparison between men and women in each group.

We then performed mixed analyses of variance (ANOVA) for the visuoperceptive tests (Corsi and HVOT cubes) and verbal tests (Digits and Semantic Fluency) with group (AD vs. MCI vs. controls) and sex (female vs. male) as inter-subject factors and content (visuospatial vs. verbal) and suppression status (without vs. inhibition) as intra-subject factors. 
Table 1. Sociodemographic variables of the sample for each group

\begin{tabular}{|c|c|c|c|c|c|c|}
\hline & $\mathrm{AD}$ & MCI & Control & $\begin{array}{l}\text { AD vs. } \\
\text { control }\end{array}$ & AD vs. MCI & $\begin{array}{l}\text { MCI vs. } \\
\text { control }\end{array}$ \\
\hline Age, years & $78.37 \pm 5.77$ & $74.43 \pm 7.42$ & $74.63 \pm 5.51$ & $\begin{array}{l}t=2.5 \\
p=0.02^{*}\end{array}$ & $\begin{array}{l}t=2.22 \\
p=0.03^{*}\end{array}$ & $\begin{array}{l}t=-0.12 \\
p=0.906\end{array}$ \\
\hline Education, years & $9.63 \pm 2.79$ & $9.3 \pm 3.74$ & $9.53 \pm 2.73$ & $\begin{array}{l}t=0.13 \\
p=0.896\end{array}$ & $\begin{array}{l}t=0.37 \\
p=0.71\end{array}$ & $\begin{array}{l}t=-0.28 \\
p=0.784\end{array}$ \\
\hline MMSE score & $21.89 \pm 1.95$ & $26.03 \pm 1.45$ & $28.13 \pm 1.67$ & $\begin{array}{l}t=-15.72 \\
p<0.00^{*}\end{array}$ & $\begin{array}{l}t=-9.17 \\
p<0.00^{*}\end{array}$ & $\begin{array}{l}t=-7.25 \\
p<0.00^{*}\end{array}$ \\
\hline
\end{tabular}

Values are expressed as means \pm standard deviations. Independent-samples $t$ tests test were used in comparisons between groups. ${ }^{*} p<0.05$.

Table 2. Sociodemographic variables of the sample by gender in each group

\begin{tabular}{|c|c|c|c|c|c|c|}
\hline & \multicolumn{2}{|l|}{$\mathrm{AD}$} & \multicolumn{2}{|l|}{ MCI } & \multicolumn{2}{|l|}{ Controls } \\
\hline & $\begin{array}{l}\text { males } \\
(n=14)\end{array}$ & $\begin{array}{l}\text { females } \\
(n=13)\end{array}$ & $\begin{array}{l}\text { males } \\
(n=15)\end{array}$ & $\begin{array}{l}\text { females } \\
(n=15)\end{array}$ & $\begin{array}{l}\text { males } \\
(n=15)\end{array}$ & $\begin{array}{l}\text { females } \\
(n=15)\end{array}$ \\
\hline Age, years & $76.64 \pm 6.11$ & $80.23 \pm 4.93$ & $76.20 \pm 7.74$ & $72.67 \pm 6.87$ & $74.87 \pm 5.23$ & $74.40 \pm 5.95$ \\
\hline Education, years & $8.64 \pm 2.89$ & $10.69 \pm 2.32$ & $8.73 \pm 3.67$ & $9.87 \pm 3.85$ & $10.13 \pm 2.42$ & $8.93 \pm 2.96$ \\
\hline MMSE score & $21.21 \pm 2$ & $22.62 \pm 1.66$ & $26.53 \pm 1.18$ & $25.53 \pm 1.55$ & $28.80 \pm 1.08$ & $27.47 \pm 1.92$ \\
\hline
\end{tabular}

Values are expressed as means \pm standard deviations.

\section{Results}

The results of the present study indicated that, in the Corsi Block-Tapping test without inhibition, there were main effects of the group $[\mathrm{F}(2,80)=3.83, \mathrm{MC}=1,942.173, p<0.05$, $\left.\eta_{p}^{2}=0.09\right]$ and of sex $\left[F(1,80)=6.28, M C=3,187.183, p<0.05, \eta_{p}^{2}=0.07\right]$, as well as for the interaction between these variables $\left[\mathrm{F}(2,80)=5.38, \mathrm{MC}=2,731.880, p<0.05, \eta^{2}{ }_{\mathrm{p}}=0.12\right]$. Pairwise comparisons applying the Bonferroni correction indicated that there was a significant trend between the MCI groups (69.13) and the controls (84.83) $(p<0.08)$. Among the AD patients (70.70) and the healthy elderly, a significant trend was also found $(p<0.10)$ (Table 3). Regarding the differences between sexes, significant differences were found between men (81.16) and women (68.77) $(p<0.01)$, with the average performance of women being significantly lower than that of men. Regarding the differences between sexes within each group (Table 3), these differences were only significant between men (84.55) and women (51.08) $(p<0.01)$ in the MCI group.

As can be observed in Table 3, the performance of women was also lower than that of men in the healthy elderly group, although this difference was not found to be significant. However, in the AD group, the performance of women was curiously higher than that of men. It is likely that the fact that female AD patients had a higher educational level than male AD patients may be influencing this relatively good performance of female AD patients in the visuospatial Corsi Block-Tapping test (we shall comment further on this issue in the Discussion section). Therefore, taking into account the results of the average performance of women and the average performance of men in the Corsi test without inhibition for each of the 3 groups, 
Table 3. Performance of men and women in the 6 tests used with AD and MCI patients as well as healthy elders

\begin{tabular}{|c|c|c|c|c|c|c|}
\hline & \multicolumn{2}{|l|}{$\mathrm{AD}$} & \multicolumn{2}{|l|}{ MCI } & \multicolumn{2}{|l|}{ Controls } \\
\hline & $\begin{array}{l}\text { males } \\
(n=14)\end{array}$ & $\begin{array}{l}\text { females } \\
(n=13)\end{array}$ & $\begin{array}{l}\text { males } \\
(n=15)\end{array}$ & $\begin{array}{l}\text { females } \\
(n=15)\end{array}$ & $\begin{array}{l}\text { males } \\
(n=15)\end{array}$ & $\begin{array}{l}\text { females } \\
(n=15)\end{array}$ \\
\hline \multicolumn{7}{|l|}{ Visuospatial } \\
\hline Blocks without inhibition & $69.43 \pm 15.42$ & $72.08 \pm 25.51$ & $84.07 \pm 31.45$ & $54.20 \pm 18.84$ & $89.20 \pm 25.26$ & $80.47 \pm 19.39$ \\
\hline Blocks with inhibition & $24.57 \pm 16.15$ & $32.62 \pm 16.55$ & $40.80 \pm 26.72$ & $24.53 \pm 15.03$ & $51.00 \pm 23.7$ & $42.67 \pm 16.66$ \\
\hline HOVT & $11.75 \pm 3.75$ & $15.54 \pm 3.24$ & $16.93 \pm 4.72$ & $14.63 \pm 4.77$ & $17.73 \pm 4.47$ & $19.43 \pm 4.55$ \\
\hline \multicolumn{7}{|l|}{ Verbal } \\
\hline Digits without inhibition & $97.79 \pm 21.52$ & $98.31 \pm 28.53$ & $91.53 \pm 29.97$ & $96.73 \pm 33.65$ & $125.93 \pm 54.59$ & $107.13 \pm 34.99$ \\
\hline Digits with inhibition & $38.14 \pm 24.08$ & $44.92 \pm 23.52$ & $58.67 \pm 36.54$ & $39.33 \pm 20.4$ & $77.60 \pm 47.73$ & $63.20 \pm 25.92$ \\
\hline Semantic fluency & $9.71 \pm 5.15$ & $10.62 \pm 3.82$ & $14.07 \pm 3.86$ & $14.27 \pm 5.06$ & $16.73 \pm 5.46$ & $13.87 \pm 3.62$ \\
\hline
\end{tabular}

Values are expressed as means \pm standard deviations.

it can be stated that the first hypothesis was partially confirmed. There were no other significant effects.

In the analysis of the results obtained in the Corsi Block-tapping test with inhibition, ANOVA indicated that there were main effects of group $[\mathrm{F}(2,80)=5.64, \mathrm{MC}=1,976.73, p<$ $\left.0.05, \eta^{2}{ }_{p}=0.124\right]$ and of the interaction between group and $\operatorname{sex}[\mathrm{F}(2,80)=4.97, \mathrm{MC}=$ $\left.1,741.287, p<0.05, \eta^{2}=0.11\right]$. Bonferroni paired comparison showed significant differences between the AD group (28.44) and the healthy elderly (46.83) $(p<0.01)$ as well as between the MCI group (32.67) and the healthy elderly $(p<0.01)$. Regarding the group-by-sex interaction, significant differences were found in the MCI group between men (41.31) and women (21.29) ( $p<0.01)$. As can be observed in Table 3, the performance of female MCI patients was lower than that of male MCI patients, confirming the first hypothesis. However, in the AD group, there was a trend towards significance in the differences between men (25.55) and women (37.4), again finding that the average of women was higher than that of men $(p<$ $0.10)$. There were no other significant effects.

The ANOVA results of the HVOT test showed main effects of group $[\mathrm{F}(2,80)=7.41, \mathrm{MC}=$ 131.513, $\left.p<0.05, \eta_{p}^{2}=0.16\right]$, as well as for the group-by-sex interaction $[\mathrm{F}(2,80)=5.193$, $\left.\mathrm{MC}=92.167, p<0.05, \eta^{2} \mathrm{p}=0.115\right]$. Once again, significant differences were found in the Bonferroni paired comparisons between the AD group (13.57) and the healthy elderly (18.58) $(p<0.01)$. In addition, there was a trend towards significance between the MCI group (15.78) and the control group $(p<0.010)$. In the group-by-sex interaction, significant differences were found in the AD group between men (11.75) and women (15.54) $(p<0.05)$. There was also a clear trend toward significance in the MCI group between men (16.93) and women (14.63) ( $p$ < 0.07). As can be observed, these results would go in the same direction as the results found previously in the other two visuospatial tests, as will be further commented in the Discussion section. There were no other significant effects.

As for the Standard Digits test without inhibition, significant differences were observed in ANOVA only for the group factor $\left[\mathrm{F}(2,80)=3.2, \mathrm{MC}=4,107.9, p<0.05, \eta_{\mathrm{p}}^{2}=0.074\right]$. Bonferroni paired comparisons showed significant differences between patients with MCI (94.13) and controls (116.53) $(p<0.05)$. There was also a significant trend between the AD group (98.04) and the controls $(p<0.08)$ (Table 3). There was no main effect of sex or of the interaction between group and sex.

In the Digits test with inhibition, ANOVA only yielded significant effects for the group factor $\left[F(2,80)=5.63, M C=5,509.68, p<0.05, \eta_{p}^{2}=0.123\right]$. Significant differences were 
obtained between the AD patients (41.41) and the controls $(70.40)(p<0.05)$ as well as between the MCI patients (49) and the controls $(p<0.05)$, confirming the previous pattern of results found in the Digits test without inhibition.

The third test (the Semantic Fluency test) used to examine the verbal component between the two sexes in each group showed main effects for the group factor $[\mathrm{F}(2,80)=$ $\left.7.145, \mathrm{MC}=151.719, p<0.05, \eta^{2} \mathrm{p}=0.16\right]$. Significant differences were found between the AD group (10.15) and the controls $(15.30)(p<0.01)$ as well as between the MCI group (14.17) and the controls $(p<0.05)$. Therefore, the results of the 3 tests used, in which the verbal component was examined, showed that this component also had a greater deterioration as cognitive deterioration increased in the $\mathrm{AD}$ and $\mathrm{MCI}$ groups, compared to the execution of the healthy elderly. There was no main effect of sex or of the interaction between group and sex, indicating that in this test the group of women did not perform worse in the more advanced phases of cognitive impairment, unlike the predictions made in the second hypothesis.

\section{Discussion}

In the absence of research on gender differences that include the entire array of normal and pathological aging, this study provides relevant data on the differences between sexes in patients with MCI and AD compared with healthy elderly and in relation to significantly lower performance in visuospatial and verbal tasks associated with the evolution of cognitive impairment.

Regarding gender differences, according to the literature, it was expected that the visuospatial component would be more affected in the group of women than in the group of men in each of the groups of deterioration. The results obtained in the present study showed a partial confirmation. There were no differences in the AD group, the scores of women being, in general, higher than those of men. A possible interpretation to explain this result may be the fact that the sample of AD women presented, curiously, an average level of years of schooling higher than that of men, although the differences in years of schooling were not statistically significant. It is possible that the higher level of schooling of AD women may compensate, to some extent, the visuospatial deficits that had been hypothesized for this group. Further studies between male and female AD patients would be necessary to see if these results are corroborated or not.

Nevertheless, these differences were found in the MCI group: women had a much lower performance than men in visuospatial tasks, which would contribute to the results of Elosúa et al. [14] - where MCI participants were not included - that state that in this stage of cognitive impairment differences between sexes appear. The results of the present research corroborate those previously found by other authors $[10,14]$; yet, this study has expanded the visuospatial tasks in the MCI group and has added the differences between sexes that were obtained.

Regarding the differences between the sexes in the healthy elderly group, both in the present study and in the study by Elosúa et al. [14], a lower average performance was obtained in the group of women than in the group of men, although in neither study were these differences significant. These results point in the same direction as other previous studies [12, 23-25].

Considering all the results, it could be pointed out that the visuospatial component of WM (with the exception of the AD group) appears to be more affected in women than in men, in line with what was indicated by previous studies, although differences have not always been significant $[11,12,14,25]$. 
Regarding the verbal component, where differences between sexes were expected to appear in the more advanced stages of deterioration, the results of this study showed that they did not appear in the healthy elderly group, nor in the AD or the MCI groups. In the work performed, both in the Standard Digits test without inhibition and with inhibition and in the Semantic Fluency, the results obtained indicated that women and men maintained a quite similar performance, even in the AD group, where the cognitive impairment was more pronounced. In the study by Elosúa et al. [14], lower scores were found in the average performance of AD females, compared to that of males, in the 2 verbal tasks (standard digits and digits with inhibition), although the differences were not significant. In the present study, after increasing and pairing the number of men and women in the 3 groups $(A D, M C I$, and healthy elderly), no significant differences appeared. Even though certain studies have found differences between sexes in verbal tasks similar to those in our study [12, 26], it is noteworthy that other studies did not, in line with the results obtained in our research $[12,26$, $27,28]$.

\section{Conclusion}

This study reports findings showing that performance in visuospatial tasks tends to depend on sex, while verbal tasks do not. However, it is possible that an Alzheimer population that has a higher degree of deterioration (MMSE score) may either maintain or change this pattern of results. More studies are warranted, with a larger sample of women and men diagnosed with MCI and AD, to better observe whether these results are replicated or not.

\section{Acknowledgments}

This work was supported by the Spanish Ministry of Economy and Competitiveness (grant number EDU2013-46437-R). The authors would like to thank Dr. María Fernández Cahill for proofreading this paper.

\section{Disclosure Statement}

The authors have no conflicts of interest to disclose. The sponsors had neither a role in the analysis or interpretation of these data, nor in the content of the article.

\section{References}

1 Weintraub S, Wicklund AH, Salmon DP: The neuropsychological profile of Alzheimer disease. Cold Spring Harb Perspect Med 2012;2:a006171.

2 Baddeley AD, Hitch G: Working memory; in Bower GA (ed): Advances on Learning and Motivation. New York, Academic Press, 1974, vol 8, pp 47-90.

3 Baddeley AD: Working memory: theories, models, and controversies. Ann Rev Psychol 2012;63:1-29.

$\rightarrow 4$ Huntley JD, Howard RJ: Working Memory in early Alzheimer's disease: a neuropsychological review. Int J Geriatr Psychiatry 2010;25:121-132.

5 Belleville S, Peretz I, Malenfant D: Examination of the working memory components in normal aging and in dementia of the Alzheimer type. Neuropsychologia 1996;34:195-207.

6 Traykov L, Raoux N, Latour F, Gallo L, Hanon 0, Baudic S, Rigaud AS: Executive functions deficit in mild cognitive impairment. Cogn Behav Neurol 2007;20:219-224.

7 Guariglia C: Spatial working memory in Alzheimer's disease: a study using the Corsi block-tapping test. Dement Neuropsychol 2007;1:392-395. 
Elosúa et al.: Gender Differences in MCI and AD

-8 Juncos-Rabadán 0, Facal D, Pereiro AX, Lojo-Seoane C: Visual memory profiling with CANTAB in mild cognitive impairment (MCI) subtypes. Int J Geriatr Psychiatry 2014;29:1040-1048.

-9 Jefferson AL, Wong S, Bolen E, Ozonoff A, Green RC, Stern RA: Cognitive correlates of HVOT performance differ between individuals with mild cognitive impairment and normal controls. Arch Clin Neuropsychol 2006:21: 405-412.

10 Cornoldi C, Vecchi TE: Visuo-Spatial Working Memory and Individual Differences. Hove, Psychology Press, 2003.

11 Heun R, Kockler M: Gender differences in the cognitive impairment in Alzheimer's disease. Arch Womens Ment Health 2002;4:129-137.

12 Irvine K, Laws K, Gale TM, Kondel TK: Greater cognitive deterioration in women than men with Alzheimer's disease: a meta analysis. J Clin Exp Neuropsychol 2012;34:989-998.

13 Beinhoff U, Tumani H, Brettschneider J, Bittner D, Riepe MW: Gender specificities in Alzheimer's Disease and Mild cognitive impairment. J Neurol 2008;255:117-122.

14 Elosúa MR, Peinado M, Contreras MJ, Reales JM, Montoro PR: The suppression effect in visuospatial and verbal working memory span tasks in patients with Alzheimer's disease: a 2-year follow-up study. Neurocase 2016;22:426-435.

15 McKhann GM, Knopman DS, Chertkow H, Hyman BT, Jack CR, Kawas CH, Klunkk WE, Koroshetzl WJ, Manlym JJ, Mayeuxm R, Mohsp RC, Morrisq JC, Rossorr MN, Scheltenss P, Carrillot MC, Thiest B, Weintraubu S, Phelps $\mathrm{CH}$ : The diagnosis of dementia due to Alzheimer's disease: recommendations from the National Institute on Aging-Alzheimer's Association workgroups on diagnostic guidelines for Alzheimer's disease. Alzheimers Dement 2011;7:263-269.

-16 Albert MS, DeKosky ST, Dickson D, Dubois B, Feldman HH, Fox NC, Gamst A, Holtzman DM, Jagust WJ, Petersen RC, Snyder PJ, Carrillo MC, Thies B, Phelps CH: The diagnosis of mild cognitive impairment due to Alzheimer's disease: recommendations from the National Institute on Aging-Alzheimer's Association workgroups on diagnostic guidelines for Alzheimer's disease. Alzheimers Dement 2011;7:270-279.

17 Lobo A, Saz P, Marcos G; Grupo de Trabajo ZARADEMP: Adaptación Española: Examen Cognoscitivo MiniMental. Madrid, TEA Ediciones, 2002.

18 Corsi PM: Human Memory and the Medial Temporal Region of the Brain. Montreal, McGill University, 1972.

19 Hooper HE: The Hooper Visual Organization Test: Manual. Beverly Hills, Western Psychological Services, 1958.

20 Tamkin AS, Jacobsen R: Age-related norms for the Hooper Visual Organization Test. J Clin Psychol 1984;40: 1459-1463.

21 Wechsler D: Wechsler Memory Scale-Revised. San Antonio, The Psychological Corporation, 1987.

-22 Peña-Casanova J, Quiñones-Ubeda S, Gramunt-Fombuena N, Quintana-Aparicio M, Aguilar M, Badenes D, Cerulla N, Molinuevo JL, Ruiz E, Robles A, Barquero MS, Antúnez C, Martínez-Parra C, Frank-García A, Fernández M, Alfonso V, Sol JM, Blesa R; NEURONORMA Study Team: Spanish Multicenter Normative Studies (NEURONORMA Project): norms for verbal fluency tests. Arch Clin Neuropsychol 2009;24:395-411.

23 Beinhoff U, Tumani H, Brettschneider J, Bittner D, Riepe MW: Gender specificities in Alzheimer's disease and mild cognitive impairment. J Neurol 2008;255:117-122.

24 De Frias CM, Nilsson LG, Herlitz A: Sex differences in cognition are stable over a 10-year period in adulthood and old age. Aging Neuropsychol Cogn 2006;13:574-587.

25 Parsons TD, Rizzo AR, Van der Zaag C, McGee JS, Buckwalte JG: Gender differences and cognition among older adults. Aging Neuropsychol Cogn 2005;12:78-88.

26 Moreno-Martínez FJ, Laws KR, Schulz J: The impact of dementia, age and sex on category fluency: greater deficits in women with Alzheimer's disease. Cortex 2008;44:1256-1264.

27 Stern Y, Albert S, Tang MX, Tsai WY: Rate of memory decline in AD is related to education and occupation: cognitive reserve? Neurology 1999;53:1942-1947.

28 Laws KR, Irvine K, Gale TM: Sex differences in cognitive impairment in Alzheimer's disease. World J Psychiatr 2016;22:54-65. 